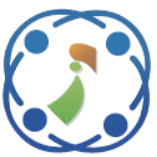

\title{
Impact of Large-Scale Wind Power Penetration on Dynamic Voltage Stability of Interconnected Power System: An Indonesia Case Study
}

\author{
Awan Uji Krismanto ${ }^{1}$ \\ Irrine Budi Sulistiawati ${ }^{1}$ \\ Herlambang Setiadi ${ }^{3 *}$ \\ F Yudi Limpraptono ${ }^{1}$ \\ ${ }^{I}$ Department of Electrical Engineering, Faculty of Industrial Technology, \\ Institut Teknologi Nasional Malang, Indonesia \\ ${ }^{2}$ Department of Electrical Engineering, Faculty of Intelligent Electrical and Informatics Technology, \\ Institut Teknologi Sepuluh Nopember, Indonesia \\ ${ }^{3}$ Faculty of Advanced Technology and Multidicipline, Universitas Airlangga, Surabaya, Indonesia \\ ${ }^{4}$ Department of Electrical Engineering, Universitas Pertamina, Indonesia \\ * Corresponding author's Email: h.setiadi@stmm.unair.ac.id
}

Ardyono Priyadi ${ }^{2}$

\begin{abstract}
The increasing penetration of wind power plant introduces a various effect on power system stability, operation and control. Unpredictable, uncertain and fluctuating circumstances can significantly affect the performance of power system. Moreover, employment of novel technologies in wind power plant significantly alter the control characteristic and operation procedure of power system to deal with load variations and fast changing of generated power from wind-based power plant. One of the main focus in integrating large scale wind power plant is how to maintain voltage stability under transient and steady state scenarios. In this paper, effects of large-scale wind power plants on voltage stability of power system is investigated. Practical test system of South-West Sulawesi, Indonesia with integration of two large scale wind power plants are considered. Hence the novelty of this paper is to introduce new and practical test system for power system stability study considering renewable energy integration. The simulation results suggest that the additional power injection from wind power plant introduces beneficial effects on power system voltage stability performance. It was monitored that the increasing power injection from wind power plant enhanced the voltage profile ( $0.96 \mathrm{pu}$ to $0.975 \mathrm{pu}$ ), voltage margin and load-ability (200 MW to $215 \mathrm{MW}$ ) of the system. Furthermore, it was also observed that additional power injection from wind power plant significantly improved the dynamic voltage stability performance of the power system, ensuring stable operation under transition stages when the power system was subjected to disturbances.
\end{abstract}

Keywords: Renewable energy, Wind power, Voltage stability.

\section{Introduction}

The power system grows significantly in proportion with the significant increase of electric power consumption. The increase of power consumptions is followed by the expansion of coverage area of power system. The transmission and distribution lines need to be extended and planned carefully to ensure reliability of electricity supply and to reach the user in urban dan remote areas. The significant growth of power demand requires a sufficient power generation to ensure a balance condition between generation and demand. Beside the capacity of power generation must meet the power demand, quality of delivered power should be maintained in allowable circumstances to ensure normal operation of power system.

In conventional power system network, the power generation is dominated by fossil fuel-based power generations. The main problems with fossil fuel are the decreasing deposits due to continuous and increasing consumption. With massive consumption of fossil fuel, it is extremely difficult to forecast and determine the availability and sustainability of fossil fuel. A safe assessment suggests that there are sufficient fossil fuel deposits to provide energy for 30 
years [1]. As main energy resources, fossil fuel such as coal, petroleum and gas have become important commodities in the world which potentially triggers conflict or even war among countries. Moreover, from environmental point of view, the increasing consumption of fossil fuel introduces some drawbacks. The fossil fuel conversion process produces pollutant and gas emission which deteriorates the environment in terms of climate change, global warming and green house effects. Therefore, it is very important to find alternative energy resources to fulfil the demand and more environmentally friendly. With all the possible disadvantages of fossil fuel, energy security has become a major concern worldwide. Implementation of novel energy resources based on renewable energy are mandatory to ensure energy supply for the customers. The integration of renewable energybased power generation on the other hand, would gradually decrease the dependency to fossil fuel, reducing economic cost and providing beneficial effects on environment.

Integration of renewable power generation on electricity grid has been increasing significantly due to some benefits of abundant sources and environmental issues. Moreover, the development of energy conversion and material technologies encourages integration of renewable energy resources-based power plants on power system network. Despites the advantages of integrating novel power plant technologies, the increasing penetration of renewable power plant introduces some challenges on power system operation. Integration of large-scale renewable energy-based power plant significantly affects power flow and stability of interconnected power system network. The increase of intermittency and uncertainty in power system as a consequence of integrating renewable energy would affect the equilibrium point of power system operations. The balance conditions dynamically change due to unpredictable power contribution from renewable energy based power generation [2].

Among renewable energy resources, wind power plant and photovoltaic based power generations are the most renewable energy-based power plants which have been connected to power system network. By 2020, $650.758 \mathrm{GW}$ capacity of wind power plants have been installed throughout the world [3]. The development of large-scale wind power plant in Indonesia has been increasing continuously. The installation of $150 \mathrm{MW}$ wind power plant at Sulawesi network encourages the increasing of clean-energy energy implementation in Indonesia power network as a contribution to reduce pollution and global warming mitigation.
Various effects of integrating large scale renewable power plant, especially wind power plant have been thoroughly studied. In general, basic configuration of wind power plant can be classified into two types according to the type of generator and energy conversion devices used to deliver power. The first type is fix speed wind turbine which utilizing squirrel cage induction generator and permanent magnet synchronous generator without power electronic devices. The second types is variable speed wind turbine which can be operated in different wind speed level due to implementation of power electronic devices as energy conversion and control devices [4-6].

As the size of wind turbine and capacity of wind power plant is increasing, it is preferable to used variable speed than fixed speed wind turbine. The main reason is the ability of the variable wind turbine to operate in different wind speed and additional isolation provided by power electronic device which can separate the mechanical and electrical side of the wind power plant. Hence, the fluctuating condition in mechanical side of wind power would not affect the electrical side or grid side. Variable speed wind power plant such as double fed induction generator and fully rated converter types provides an additional reactive power to the system. The ancillary services of wind power plant in providing reactive power injection to the system might enhance the system voltage profiles which consequently improves loadability of the system [7, 8]. Even though the additional power injection from wind power plant can help to fulfil the load demand and enhanced the voltage profiles, uncertain power injections from wind power plant and features of wind power generation technologies potentially introduce novel stability concerns in power system operation and control $[9,10]$. One of the main concerns of integrating wind power plant is maintaining voltage stability of the power system [11]. Effect of wind power on a small test power system is studied in [12]. It was monitored that in power system with dominant wind power, the system load-ability decreased with the increase of wind power penetration. Moreover, at high wind power situation more oscillatory condition was observed when power system is subjected to disturbances.

Fast change power injection from wind power plant under fluctuating condition of wind speed might influence dynamic/ transient voltage stability. Wind power plant usually situated in coastal or off-shore area. This requires a long transmission network to deliver power for the load. The existence of long transmission might bring a weak power system operation especially when power system operated 
under heavy loading scenarios. Hence, voltage instability risk increases as an consequence of those weak transmission lines [13]. Integration of wind power plant introduced a novel challenge on system stability due to interaction between control system of wind power plant and conventional power plant [14], [15]. Furthermore, as a portion of generated power from conventional power plant is replaced by injected power from wind power plant, it potentially reduces system damping and deteriorates system dynamic performance.

The massive development of power conversion technologies in wind power plant introduces a challenge in power network operation and control. The utilization of power electronic devices as energy conversion and power conditioning devices may either enhance wind power injection or deteriorate stability of power system due to less inertia characteristic of such device configuration. Moreover, implementation of asynchronous generator requires a certain amount of reactive power from the network. Hence, it potentially influences the reactive power flow and voltage stability. Therefore, a robust control algorithm is required in wind power plant to ensure continuity of electricity service and maintain voltage stability of the power system with high penetration of wind power plant. Hence, dynamic and static voltage stabilities can be maintained under fluctuated power injection from wind power plant [16].

With the possible advantages and drawbacks of having a such large-scale wind power plant in power system, it is necessary to provides a comprehensive analysis of those impacts. However, most of the previous research only presents the investigation of wind power impact on test power system. So far, less paper provides investigation of

wind power effects on practical power system. Therefore, this paper addresses a comprehensive analysis of impacts of integrating wind power plant on dynamic and static voltage stability of a practical power system in Indonesia. It is expected that the obtained results can be used as consideration and recommendation for planning the renewable energy integration. The remainder of the paper is organised as follows. Wind power plant model is presented in Section II. The simulation results are presented and discussed in Section III. Eventually, conclusions and contributions of this paper are highlighted in Section IV.

\section{Wind power plant dynamic model}

Generated power from wind power plant is

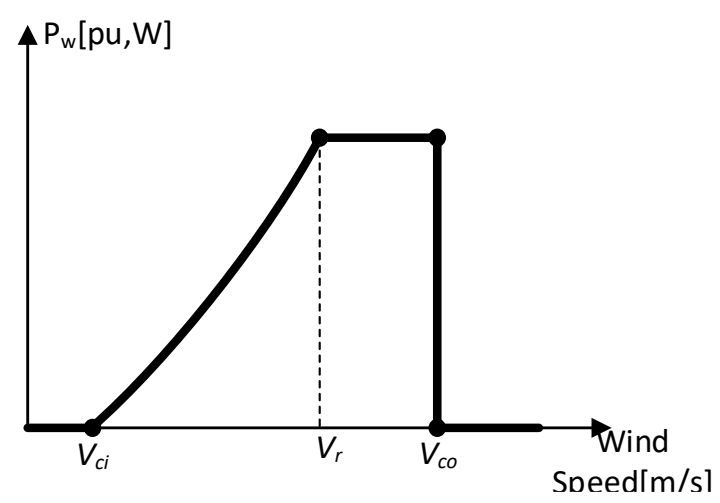

Figure. 1 Wind power curve

influenced by mechanical characteristic of wind turbine, power output curve and actual wind speed values. For a specific wind turbine, a typical power curve of a wind-based power generator is depicted in Fig.1. Wind turbine normally operates between cutin $\left(V_{c i}\right)$ and cut-off speed $\left(V_{c o}\right)$. The generated power increases proportionally as wind speed increased between those limits, and reach the nominal values when the wind speed is equal to rated speed $\left(V_{r}\right)$. However, beyond those limits the wind turbine is not operated due to efficiency and safety reasons respectively [17].

Using the presented wind power curve, the generated power from wind power plant can be formulated as given by the following equation [18], [19].

$P_{w}\left(v_{w}\right)\left\{\begin{array}{c}0 \text { for } v<v_{c i} \text { or } v>v_{c o} \\ \frac{v_{w}-v_{c i}}{v_{r}-v_{c i}} P_{w r} \text { for } v_{c i} \leq v \leq v_{r} \\ P_{w r} \text { for } v_{r}<v<v_{c o}\end{array}\right.$

Where $P_{w}$ and $P_{w r}$ represent a power output at a particular wind speed and the equivalent rated power output of wind power plant. In this research, power injection from wind power plant is increasing proportionally to investigate impacts of increasing wind power penetration on power system voltage stability.

As mentioned previously, fluctuating conditions of wind speed result in fluctuating power injection from wind power plant. Hence, a variable speed operation capability of wind power plant is required to ensure stabile operation and reliability of electricity services. In this research, a fully rated wind power generation is considered. Those direct driven wind power plant technology provides a full service and flexible operations of back to back inverter system for controlling and maintaining a stable 


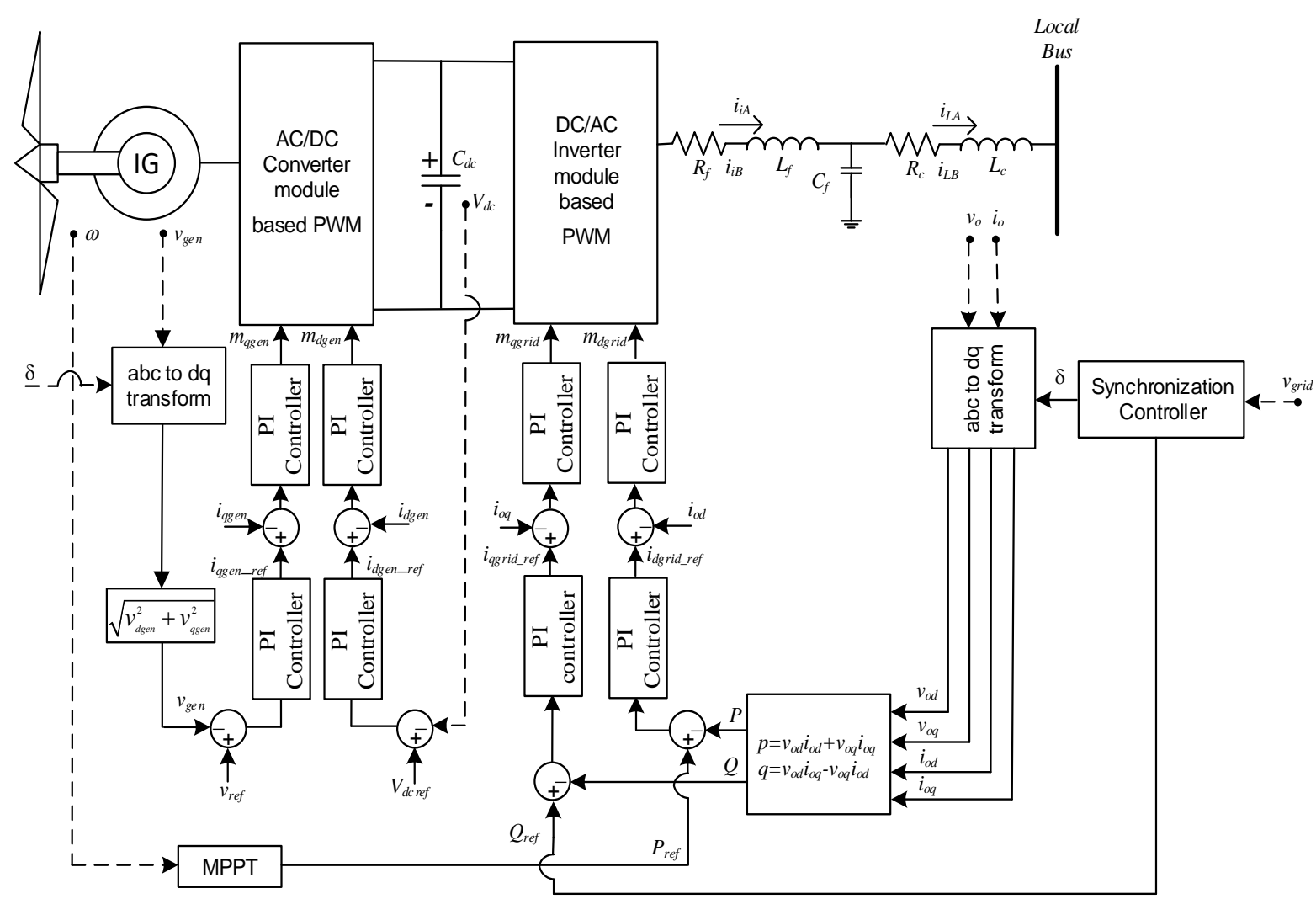

Figure. 2 Dynamic model of wind power generation

generated power under fast change of wind speed. The dynamic model fully rated wind power generator is comprising of current model of induction generator and a detailed model of back to back inverter system as presented in [20,21]. In this research, it is assumed that the wind power plant is operated at a constant pitch angle. Hence, only controllers of back to back inverter system is considered in the dynamic wind generation model.

A block diagram of dynamic model of fully rated wind generation is depicted in Fig. 2. Control system of fully rated wind power generation consists of two major parts; generator and grid side controllers. The generator-side controller allows variable speed operation capability under fluctuating condition of wind speed. Control signal for generator-side converter is obtained from reference values of generator and DC link voltages. Hence, the stable operation of fully rated wind power plant can be well maintained. Grid-side controller is responsible for providing a stable output power by controlling the active and reactive power flow to the grid [22].

Moreover, it also enhances the power quality by reducing total harmonic distortion due to high frequency switching operation of the inverter system.

In grid connected mode of wind power plant, synchronisation procedure is important to ensure

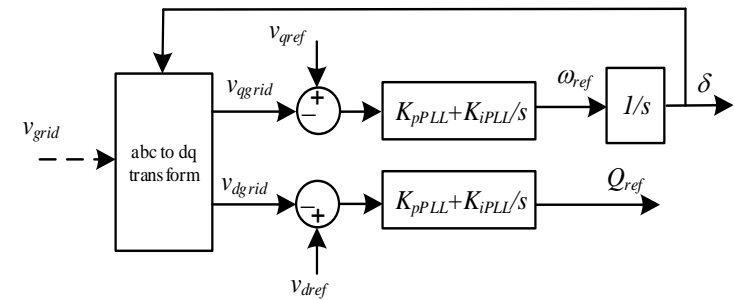

Figure. 3 PLL controller

stable operation of power system in different power injection level from wind power plant.

The synchronisation controller determines reference angle, frequency and voltage values. A synchronized operation between wind power plant and synchronous machine-based power plants is maintained using phase lock loop (PLL) controller as depicted in Fig. 3.

Dynamic behaviour of the PLL controller is represented by a set of auxiliary state variables $\left(\varphi_{d P L L}, \varphi_{q P L L}\right)$ as given by the following equation.

$$
\frac{d \varphi_{d P L L}}{d t}=v_{d r e f}-v_{q g r i d}, \frac{d \varphi_{q P L L}}{d t}=v_{q r e f}-v_{d g r i d}
$$


The calculated reference reactive power and angular frequency from PLL controller are given by the following equations.

$$
\begin{aligned}
& Q_{\text {ref }}=K_{i P L L} \varphi_{d P L L}+K_{p P L L}\left(v_{d r e f}-v_{\text {dgrid }}\right) \\
& \omega_{\text {ref }}=K_{i P L L} \varphi_{d P L L}+K_{p P L L}\left(v_{\text {qref }}-v_{\text {qgrid }}\right)
\end{aligned}
$$

The obtained reactive power and angular frequency reference values from synchronization controller are then applied to the local controller of wind power plant which comprising of generator and grid-side converter control algorithms.

The generator-side converter control is responsible for maintaining a stable condition of terminal generator and DC link voltage, allowing variable speed operation of the induction generator. Measured terminal generator and DC link voltage are compared to their reference values. The determined errors are then controlled using conventional PI control method to derive reference values of direct and quadrature currents. By considering $\beta_{d g e n}$ and $\beta_{\text {qgen }}$ as auxiliary state variables of outer control loop of generator side converter, state equations of the controller can be stated as.

$$
\frac{d \beta_{d g e n}}{d t}=v_{d r e f}-v_{d c}, \frac{d \beta_{q g e n}}{d t}=v_{g e n \_r e f}-v_{g e n}
$$

The reference currents of generator side converter are given by.

$$
\begin{aligned}
& i_{d g e n \_r e f}=K_{i 21} \beta_{d g e n}+K_{p 21} v_{d r e f}-K_{p 21} v_{d c} \\
& i_{\text {qgen_ref }}=K_{i 11} \beta_{\text {qgen }}+K_{p 11} v_{\text {gen_ref }}-K_{p 11} v_{g e n}
\end{aligned}
$$

Output variables from the outer control loop are then applied to inner current control loop as reference values and compared to the actual values of generator currents $\left(i_{\text {dgen }}, i_{\text {qgen }}\right)$.

A similar algorithm is implemented to the current control loop to determine the modulation indices $\left(m_{d g e n}^{*}, m_{\text {qgen }}^{*}\right)$ for the generator-side converter. These modulation indices are afterward employed as control variables of PWM switching scheme for the converter. Auxiliary state variables of $\gamma_{d g e n}$ and $\gamma_{q g e n}$ are required to provide state equation of the current controller as given by $\frac{d \gamma_{d g e n}}{d t}=i_{d g e n \_r e f}-i_{d g e n}, \frac{d \gamma_{q g e n}}{d t}=i_{\text {qgen_ref }}-$ $i_{\text {qgen }}$

The algebraic equations of modulation indices reference signal for generator side converter are given by.

$$
m_{d g e n}^{*}=K_{i 41} \gamma_{d g e n}+K_{p 41} v_{d g e n \_r e f}-K_{p 41} i_{d g e n}
$$

$$
m_{q g e n}^{*}=K_{i 31} \gamma_{q g e n}+K_{p 31} v_{q g e n \_r e f}-K_{p 31} i_{q g e n}
$$

Similar to the generator-side control, the grid-side inverter control in fully rated converter-based wind power plant is consisting of slow response outer and fast response inner control loops. In the outer control loop, the calculated active and reactive power reference values are compared to the measured active and reactive output power. The obtained error is then regulated by PI controller, yielding the reference values for the inner current control loop. By considering $\beta_{\text {dgrid }}$ and $\beta_{\text {qgrid }}$ as auxiliary state variables of the outer control loop of grid-side converter, state equations of the controller can be stated in the following equations.

$\frac{d \beta_{d g r i d}}{d t}=P_{r e f}-P, \frac{d \beta_{q g r i d}}{d t}=Q_{r e f}-Q$

The reference currents of grid-side converter are calculated as follows.

$i_{\text {dgrid_ref }}=K_{i 22} \beta_{\text {dgrid }}+K_{p 22} P_{\text {ref }}-K_{p 22} P$

$i_{\text {qgrid_ref }}=K_{i 12} \beta_{\text {qgrid }}+K_{p 12} Q_{\text {ref }}-K_{p 12} Q$

By comparing and regulating the difference between reference $\left(i_{\text {dgrid_ref }}, i_{\text {qgrid_ref }}\right)$ and measured output current $\left(i_{o d}, i_{o q}\right)$, the modulation indices references $\left(m_{\text {dgrid }}^{*}, m_{\text {qgrid }}^{*}\right)$ for the grid-side inverter are determined. These modulation indices are afterward employed as control signal of PWM switching scheme for the inverter. Auxiliary state variables of $\gamma_{\text {dgrid }}$ and $\gamma_{\text {qgrid }}$ are required to provide state equations of the current controller loop as given by 
$\frac{d \gamma_{d g r i d}}{d t}=i_{d g r i d \_r e f}-i_{0 d}, \frac{d \gamma_{q g r i d}}{d t}=i_{q g r i d \_r e f}-i_{0 q}$

The algebraic equations of modulation indices reference signal for grid-side inverter are given by.

$$
m_{q g r i d}^{*}=K_{i 32} \gamma_{q g r i d}+K_{p 32} v_{q g r i d \_r e f}-K_{p 32} i_{o q}
$$

$$
m_{d g r i d}^{*}=K_{i 42} \gamma_{d g r i d}+K_{p 42} v_{d g r i d \_r e f}-K_{p 42} i_{o d}
$$

\section{Voltage stability analysis}

\subsection{Static voltage stability}

Voltage stability analysis in power system can be classified according to the type of disturbance, or the time frame over which the instability may occur [23]. Due to the type of disturbance, large voltage instability can be defined as the ability of power system to maintain voltage after suffered a large disturbance such as faults, loss of generator or contingencies. While, the ability of power system to maintain voltage after being subjected to small disturbance such as incremental or small load change is defined as small disturbance instability. Regarding the time span, voltage instability concerns are classified into long term stability (few minutes to hour), mid-term stability (10 seconds to few minutes) and short term or transient voltage stability (0-10 minutes). Transient or short-term voltage stability considers fast dynamic response of the system voltage under change of operating point. While, longterm voltage stability involves slower-acting of the equipment in responding the disturbances.

Most of the incidences of voltage instability can be observed as slow phenomenon of voltage variations over a certain time-span followed by rapid change of voltage magnitude when it approaches near to the instability. This phenomenon can be analysed as "static phenomenon" and classified into static voltage stability. To assess the static stability concerns, two curves that have been popularly used are $\mathrm{P}-\mathrm{V}$ and $\mathrm{Q}-\mathrm{V}$ curves. The typical $\mathrm{P}-\mathrm{V}$ and $\mathrm{Q}-\mathrm{V}$ curves is depicted in Fig. 4. The P-V curve shows the system voltage under different values of real power and fixed load power factor. The P-V curve is applied to determine the maximum real power loading margin which also known as static voltage stability margin. The power system load is gradually increased and stopped when the voltage collapse point or nose of the PV curve is reached [24].

Reactive power is key to voltage stability. Even though reactive power is easier to generate compared to active power, it is more difficult to transmit. At higher loading conditions, transmission lines are unable to deliver reactive power. It was also been observed that the greater distance of the reactive power source from the reactive power demand, the greater required amount of reactive power compensation and more difficult to control the voltage level. Therefore, the unbalance or deficit of reactive power either locally or globally leads to poor voltage profiles. Under fluctuating power generation and increasing in loading conditions, it potentially led to voltage collapse. As depicted in Fig. 1, reactive power margin which indicates how much further the loading on a particular bus can be increased before voltage collapse is reached, is measured as a distance between lowest reactive power point in QV curve and the voltage axis [25]. By investigating PV and QV curves, voltage stability margin and loading maximum can be determined to ensure stable operation of power system.

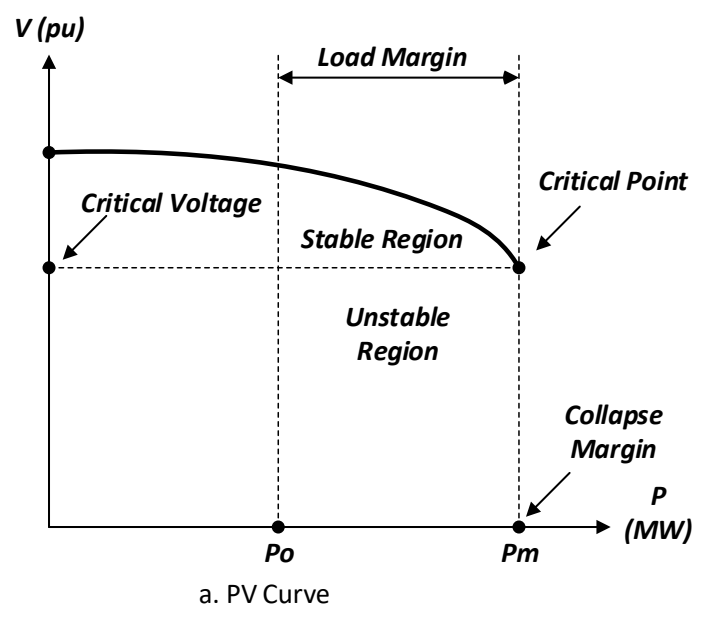

(a)

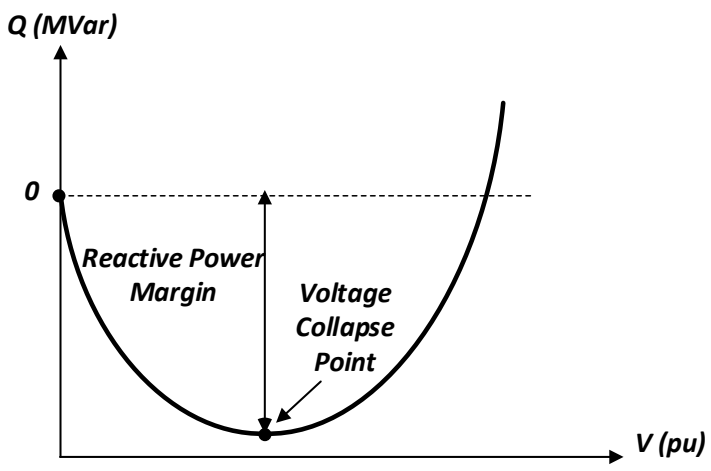

b. QV Curve

(b)

Figure. 4 Typical: (a) PV and (b) QV Curve 


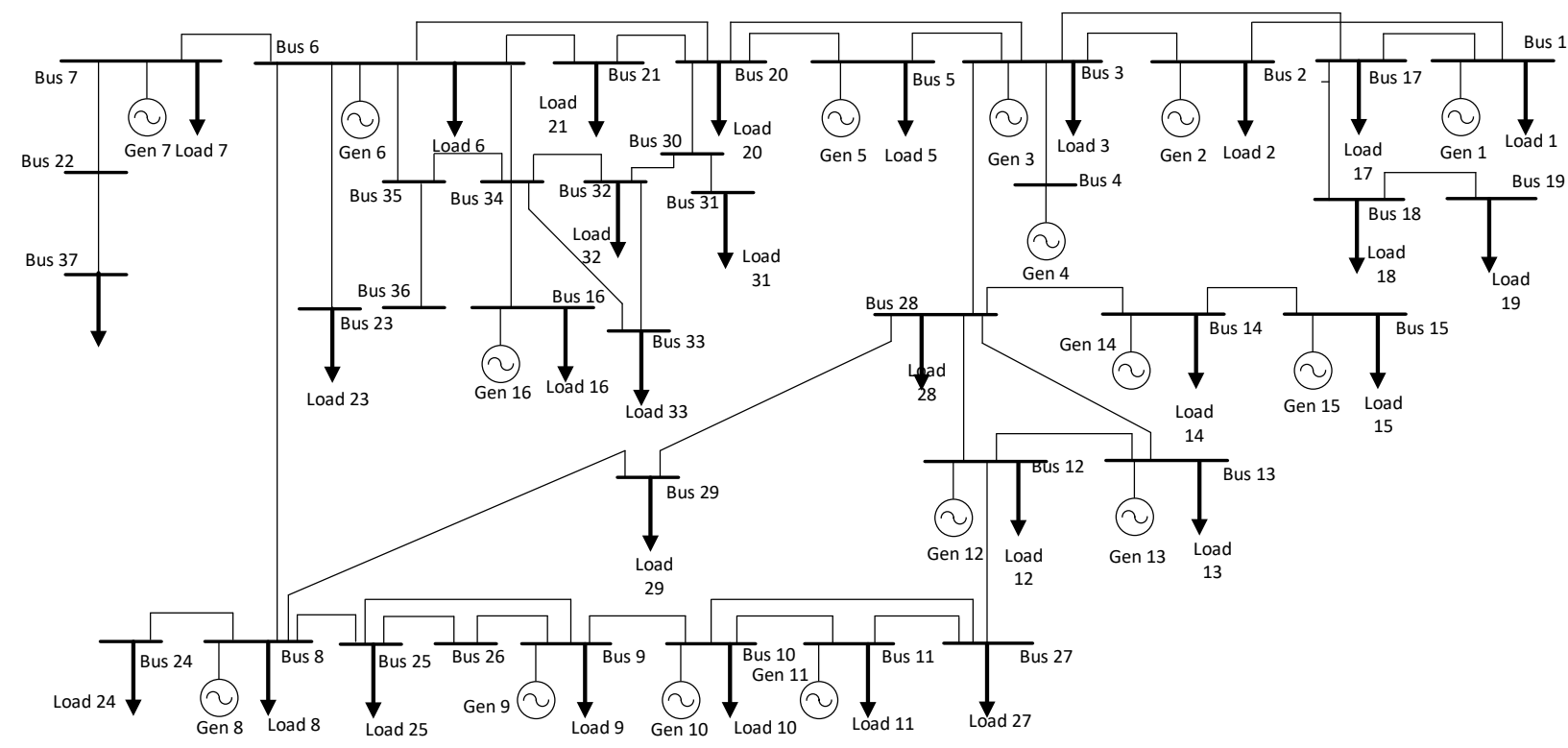

Figure. 5 South-west Sulawesi $150 \mathrm{kV}$ network

\subsection{Dynamic voltage stability}

Under fluctuating conditions or after being subjected to a disturbance, an oscillatory condition is monitored. When power system is able to maintain stability, the oscillation would decrease and eventually diminish after a new equilibrium point is reached. On the other hand, an increasing magnitude of oscillation reflects unstable situations. With the increase of uncertainties in power generation andload demand, oscillatory circumstances are frequently observed. Therefore, static stability analysis is not sufficient to capture the performance of power system.

The dynamic response should be carefully observed to provide a complete picture of system dynamic behaviour. This involves time-domain simulations. The power system component are represented by a set of not-linear equations which is solved using time integration methods [26]. The dynamic analysis is also required to determine the maximum allowable critical clearing time to ensure stable operation of power system [27, 28].

\section{Results and Discussions}

An interconnected power system network comprising of 16 synchronous generators was considered. The investigated network was South West Sulawesi $150 \mathrm{kV}$ system, with two $150 \mathrm{MW}$ wind power plants in Sidrap (bus 28) and Jeneponto (bus 9) as depicted in Fig. 5 [29]. Fully rated wind power conversion system technology as described in the previous section is considered. The implemented wind power technology provides a better variable speed operation capability due to independent control capability of generator and grid side inverter.

The discussions were focused on impact of increasing wind power penetrations on voltage profiles and dynamic responses of bus voltage when the system was subjected to small and large disturbances. Voltage profiles and static voltage stability margin would be evaluated to determine the maximum loading capability of the investigated system under different power injection from wind power plant. Moreover, the system dynamic performance would be evaluated to capture the risk of instability under different wind power penetration when fault and fast changing loading circumstances are experienced.

Additional power injection from large-scale wind power plants altered the direction of power flow and hence influenced the losses of the system. As power injection from wind power plant may change the power flow direction of the interconnected power system, it also influences the transmission line congestion. Consequently, integration of a such power source potentially either enhances or deteriorates voltage profiles at feeder endings depending on its capacity and location. Impact of different wind power penetration on steady state system performance, in particular system losses is depicted in Fig. 6. It was clearly monitored that the increasing wind power penetration introduces a beneficial effect on system losses. With wind power penetration, the real power losses decrease around $20 \%$ from $26.82 \mathrm{MW}$ in base case scenario to 21.23 


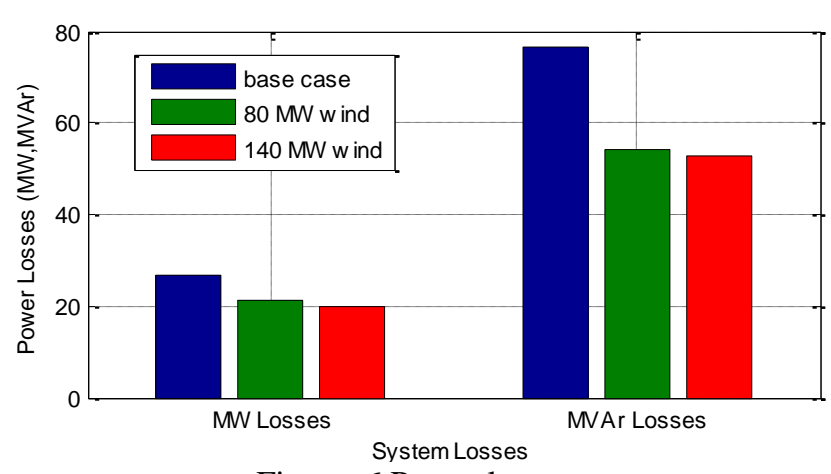

Figure. 6 Power losses

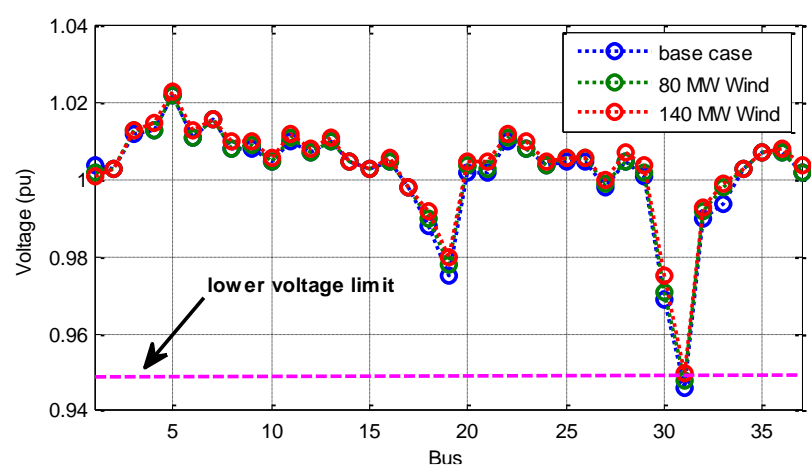

Figure. 7 Voltage profiles

MW and 20.07 MW with 80 MW and 140 MW wind power penetrations respectively. Moreover, the significant decrease was observed in reactive power losses as indicating by $25 \%$ decrement from 76.75 MVAr in base scenario to 54.20 MVAr and 53.02 MVAr in $80 \mathrm{MW}$ and $140 \mathrm{MW}$ wind power penetrations respectively. As power injection from wind power increases, the power losses decrease proportionally. With the decrease of system losses, it would provide an enhancement of system voltage profiles.

Impact of large-scale wind power penetrations on voltage profiles is depicted in Fig. 7. Two different level of power injections from wind power plants are considered. In general, it was monitored that at higher power injection from wind power plant, the improvements of voltage profile of the buses are observed. Significant enhancements of voltage profiles were monitored at bus 19 and bus 31 . In base case scenario without wind power penetration, the voltage profiles at bus 19 and 31 were 0.96 pu and 0.948 pu respectively. As wind power was gradually increased, the voltage profiles at those buses improved to 0.972 and 0.952 respectively. Especially for bus 31 , the wind power penetration contributes for removing under voltage concern.

Voltage profile is an important indicator to determine the allowable load demand which can be connected to the system. Capability to maintain voltage profiles under different loading conditions is important to ensure stable operation of power system under sudden change of generated power from available generators and fluctuating load circumstances. In a weak grid with marginal values of voltage profiles, the sudden increase of load demand and loss of power generation potentially deteriorates stability of power system. In this condition, further increase of load demand potentially lead to the risk of voltage collapse which result to partially or even entire black-out.

The voltage stability analysis involves a capability transfer of real power from one area to another area in power system and its effects to the system voltage. The voltage profiles of the interconnected power system network are mainly influenced by power balance between generation and demand, power flow direction and transmission network congestion management. As wind power plant inject a certain amount of power to the grid, it potentially influences voltage margin and maximum loading condition of power system. Maximum loading condition can be assessed using PV curve which indicates the voltage

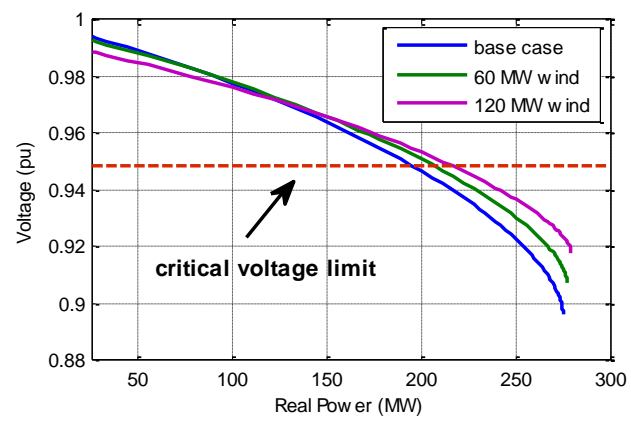

(a)

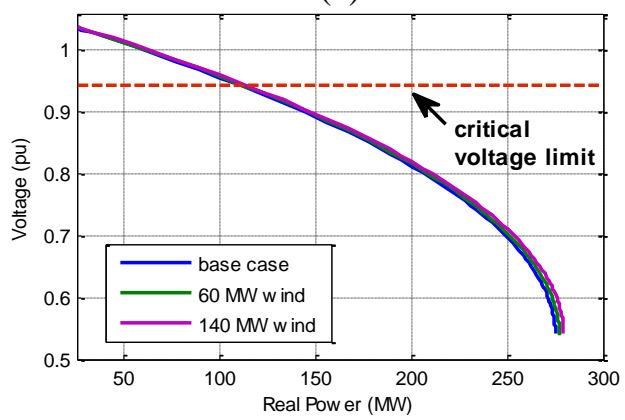

(b)

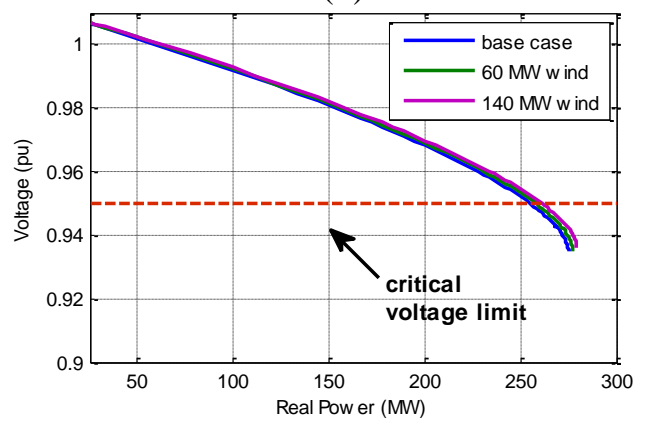

(c)

Figure. 8 PV Curves of bus: (a) 19, (b) 31 and (c) 32 


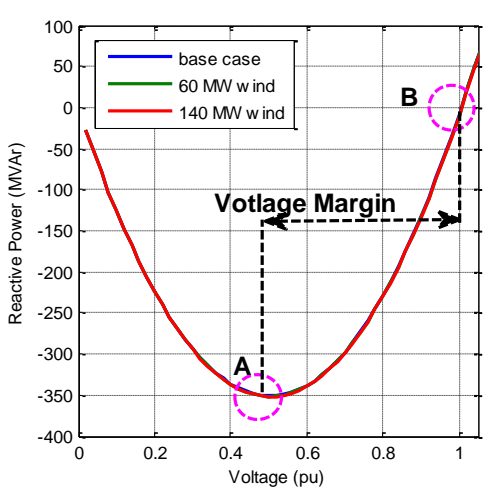

Point A

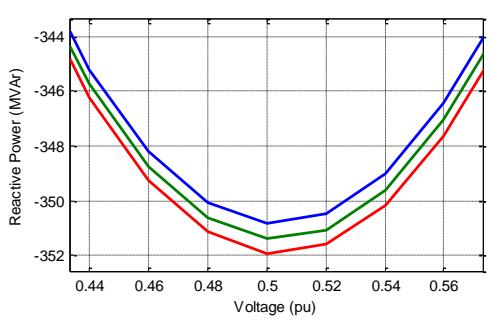

Point B

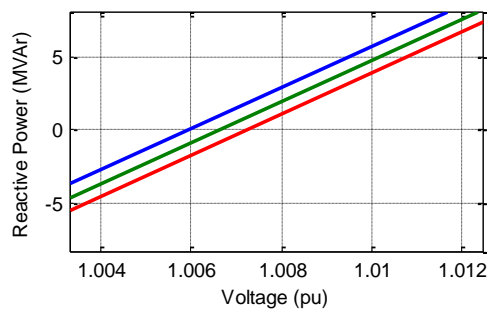

(a)

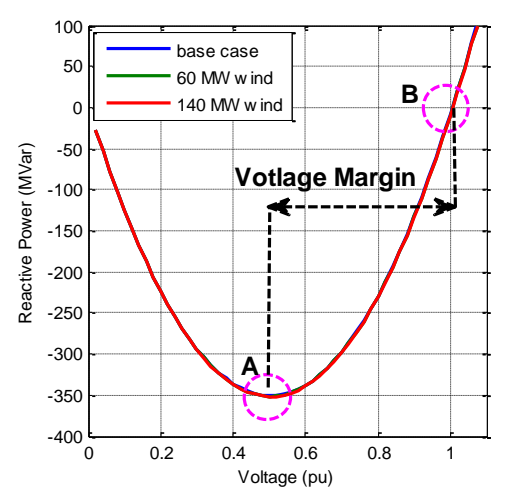

Point A

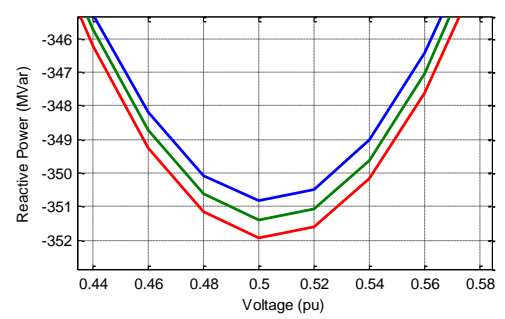

Point B

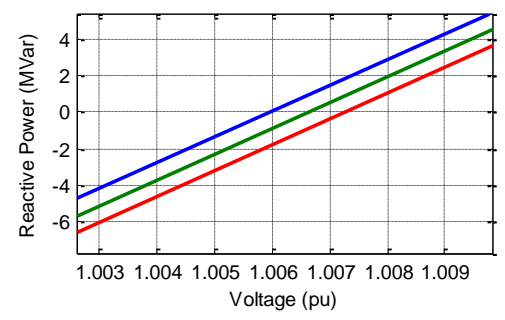

(b)

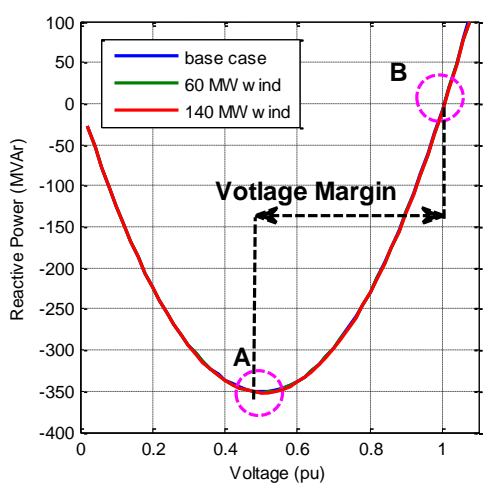

Point A

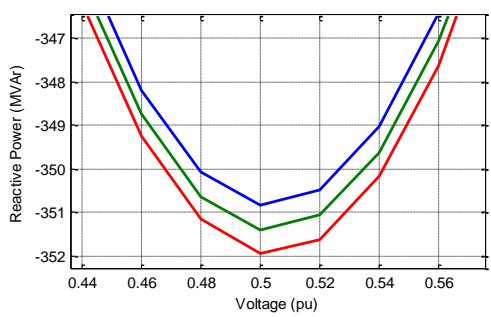

Point B

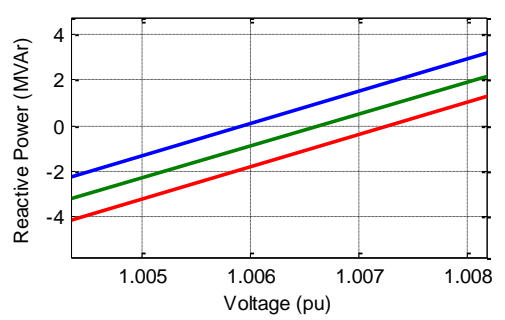

(c)

Figure. 9 QV curve of bus: (a) 19, (b) 31, and (c) 32

variation at a particular bus in different loading scenarios.

Impacts of different wind power penetration on load-ability and voltage margin of the selected bus is depicted in Fig. 8. As depicted in Fig.8, higher power injection from wind power plant contributes to improve bus voltage. The improvements of voltage profiles are followed by the higher load demand which can be supplied without causing under voltage or even voltage collapse. It was clearly monitored that maximum loading points of the selected buses slightly shifted to the right side with the increased of wind power penetrations. At bus 19, under base case scenario without wind power, the critical voltage limit was reached at $200 \mathrm{MW}$ loading condition. The loading limit increased to $210 \mathrm{MW}$ and $215 \mathrm{MW}$ with $80 \mathrm{MW}$ and $140 \mathrm{MW}$ wind power penetration respectively. Similar trends were observed at bus 31 and 32, indicating by slight increase of loading limit under higher power injection from wind power plants. The increase of loading limit indicated the increase of voltage stability margin and load-ability of those buses. As the capability of the investigated power system to maintain voltage profiles in higher maximum loading condition increased, voltage stability margin also increased proportionally. The enhancement of voltage stability margin reflects more robust condition of the system static voltage stability.

The critical feature of wind power plant involves unpredictable and fluctuating change of generated power according to wind conditions. Therefore, power conditioning is required to ensure stable power injection from such renewable energy-based power plant. Most wind power generation is comprising of asynchronous generator and power converter as interfacing devices. This configuration is required to facilitate flexible operation capability under different wind speed circumstances. On the other hand, the utilization of asynchronous generator technology in wind power plant requires a certain amount of reactive power from the grid for facilitating energy conversion. As absorption of reactive power of wind power generation depend on generated active power from wind turbine, it may affect the flow of reactive power and eventually bus voltages. Deficit of reactive 


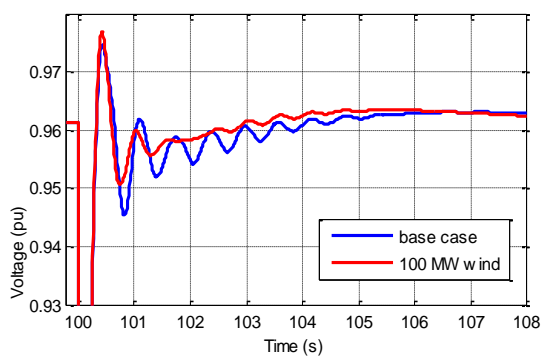

(a) 1 Bus 19 under fault

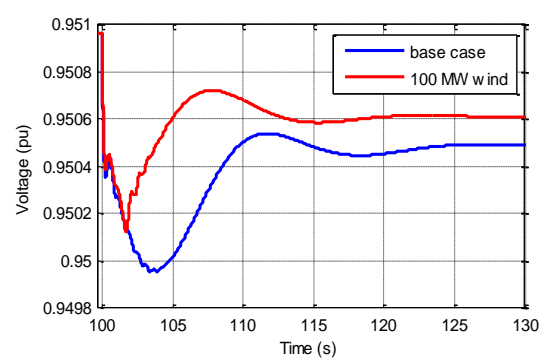

(b) 1 Bus 19 under load change

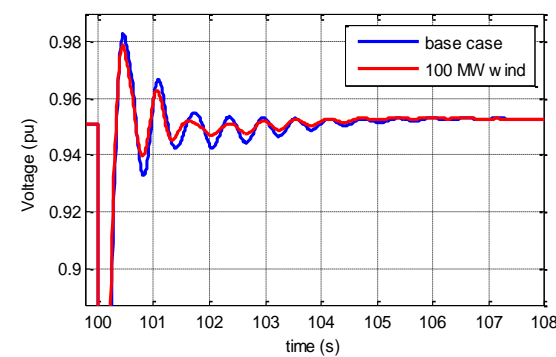

(a) 2 Bus 31 under fault

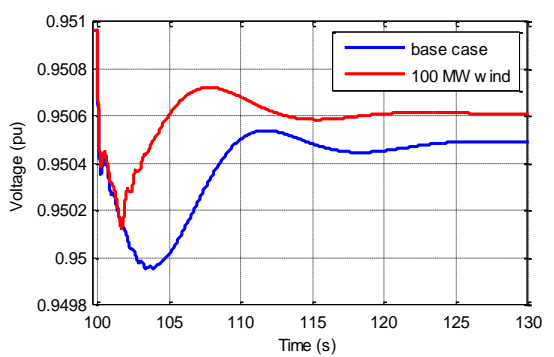

(b) 2 Bus 31 under load change

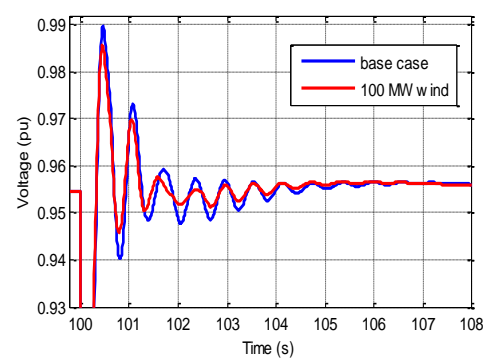

(a) 3 Bus 32 under fault

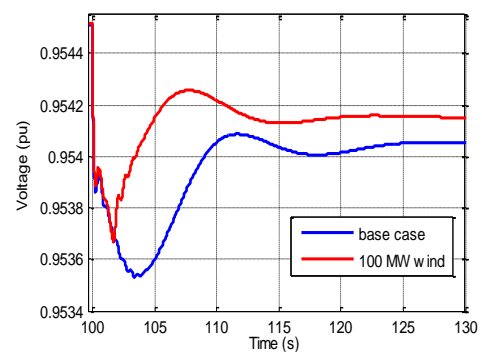

(b) 3 Bus 32 under fault

Figure. 10 Dynamic voltage response under: (a) fault and (b) load change conditions

power with the increasing of loading condition may lead to unstable condition or even local or globally interruption due to poor voltage profiles. Similar to PV curve analysis, voltage stability condition can also be assessed by analysing how the fluctuation of reactive power influence the bus voltages. The influence of reactive power variation injection and absorption on bus voltage can be monitored through QV curve.

Fig. 9 represents QV curve of the selected bus in base case scenario and with different wind power penetrations. It was monitored that wind power penetration introduces a positive impact on electrical power network operation. The voltage margin of the selected bus slightly increased with the increased of wind power penetration. Thus, improving voltage stability of the system. From PV and QV curve analysis, it was monitored that additional power injection from wind power plant enhanced voltage profiles and loadability as indicated by the increase of system abilility to maintain voltage profile at higher maximum loading conditions and reactive power demand. The increase of system loadability highly correlated with higher flexibility of power system in maintaining voltage profiles under different loading conditions. More flexibility of power system in maintaining voltage profiles reflects enhancement of static voltage stability performance.

The static voltage stability performance of power system as analysed using PVand QV curves, allows examination of voltage stability in a wide range of system condition of power system and provides much insight of the nature of the problem and various contributing factors. Dynamic analysis, on the other hand, is useful for a detailed study of the risk of voltage fluctuation and collapse situations. The dynamic analysis is required to capture the system dynamic performance in particular response of system voltage under transient conditions.

In this paper, two scenarios of transient phenomenon in power system is considered to investigate dynamic voltage stability performance of power system involving the effect of power injection from wind power plant. The dynamic voltage stability under faulty and load changes conditions in base-case and with $100 \mathrm{MW}$ wind power penetration is depicted in Fig. 10. It was monitored that additional wind power injection enhanced dynamic voltage stability performances. After being subjected to a fault, more oscillatory condition of bus voltage was experienced when there is no power injection from wind power plant. In base case scenario, longer oscillatory conditions are also monitored, indicated longer time to reach steady state values eventhough the power sytsem has reached the new equilibrium point. With additional $100 \mathrm{MW}$ power injection from wind power plant, more damped response was observed, reflected by lower oscillatory amplitude and faster settling time.

In second scenario, effect of wind power plant integration on dynamic voltage stability performance was investigated when the real power of the entire connected load was suddently increased by $5 \%$. Similarly, improvement of dynamic voltage stability was monitored when system was subjected to load change. Under transition stage, more fluctuating 
condition was observed in base-case scenario without wind power injection as indicated by lower undershoot and longer settling time. Furhtermore, integration of wind power plant enhances system dynamic response, indicated by smaller undershoot and faster settling time. As a result, novel equilibrium point can be reached faster and hence dynamic voltage stability can be maintained. The enhancement of dynamic voltage stability response under load change scenario was mainly caused by the contribution of wind power plant in replacing a certain amount of the generated power from conventional synchronus generator based power plant. As the wind power plant implement power electronic devices as interface devices, the control action of those devices provides faster response than a conventional power plant fueled by fossil fuel such. Therefore, when an equilibrium operating point changes due to disturbance, faster response from wind power plant can significantly help the power system to regain the equilibrium point or reach the novel a stable operating point.

Eventhough, faster response is the advantages of having a such wind power plant, replacing a certain amount of generated power from synchronous generator based power plant may have either decrimental or beneficial effects. The decrimental effect corelates to the decrease of sytem inertia. Lack of system inertia would reduce damping of the system which may lead to more oscillaory condition when the large disturbance occurred. On the other hand, having more wind power plant would reduce generator stress due to less responsible for providing power to the system. Lower stress condition of the generator would increase generator efficiency and spinning reserve of the system.

\section{Conclusions}

Impacts of wind power integration on power system voltage stability were investigated in this paper. Enhancement of static voltage stability was experienced in proportion with the increase of wind power. As wind power injection increased, higher voltage profiles were monitored. Moreover, system loadability and votlage-margin enhanced with the increased of wind power injection, indicating more flexibility to maintain voltage profiles and improvements of static voltage stability performance under higher maximum loading conditions. Additional power injection from wind power plant also contributes to improve dynamic stability performance when power system experienced a sudden change of stable operating point. Less inertia features of wind power plant and implementation of fast control action of power electronic devices provides a faster response to regain an equilibrium point or reach a novel stable operating point after being subjected to disturbance. The enhancement of dynamic voltage performance of power system is reflected by more damped voltage response and faster settling time to reach a stable steady state voltage condition.

\section{Conflicts of interest}

"The authors declare no conflict of interest."

\section{Author contributions}

"Conceptualization, Awan Uji Krismanto, Irrine Budi Sulistiawati and F Yudi Limpraptono; methodology, Awan Uji Krismanto, Ardyono Priyadi and Herlambang Setiadi; Awan Uji Krismanto, F Yudi Limprapto and Muhammad Abdillah; validation, Awan Uji Krismanto, Irrine Budi Sulistiawati and F Yudi Limpraptono; formal analysis, Awan Uji Krismanto, Ardyono Priyadi and Herlambang Setiadi; investigation, Awan Uji Krismanto and Muhammad Abdillah; resources, Awan Uji Krismanto; writing original draft preparation, Awan Uji Krismanto; writing review and editing, Irrine Budi Sulistiawati, Ardyono Priyadi and F Yudi Limpraptono; visualization, Awan Uji Krismanto, Muhammad Abdillah, and Herlambang Setiadi. All authors have read and agreed to the published version of the manuscript".

\section{References}

[1] D. Infield and L. Freris, Renewable Energy in Power Systems, John Wiley \& Sons, 2020.

[2] F. M. Gonzalez-Longatt, Advanced Smart Grid Functionalities Based on PowerFactory. Switzerland: Springer International Publishing, 2018.

[3] J. D. Pitteloud, "Global Wind Installations", 2020.

[4] R. Akbari, A. Izadian, and R. Weissbach, "Quasi Self-Excited DFIG-Based Wind Energy Conversion System", IEEE Trans. Ind. Appl., 2021.

[5] J. Wang, D. Bo, Q. Miao, Z. Li, X. Wu, and D. $\mathrm{Lv}$, "Maximum power point tracking control for a doubly fed induction generator wind energy conversion system based on multivariable adaptive super-twisting approach", Int. J. Electr. Power Energy Syst., Vol. 124, p. 106347, 2021.

[6] K. A. Singh and K. Chaudhary, "Design and development of a new three-phase AC-DC single-stage wind energy conversion system", IET Power Electron., Vol. 14, No. 2, pp. 302- 
312, 2021.

[7] A. Rosini, A. Labella, A. Bonfiglio, R. Procopio, and J. M. Guerrero, "A review of reactive power sharing control techniques for islanded microgrids", Renew. Sustain. Energy Rev., Vol. 141, p. 110745, 2021.

[8] B. B. Adetokun and C. M. Muriithi, "Impact of integrating large-scale DFIG-based wind energy conversion system on the voltage stability of weak national grids: a case study of the Nigerian power grid", Energy Reports, Vol. 7, pp. 654666, 2021.

[9] Z. Yue, Y. Liu, Y. Yu, and J. Zhao, "Probabilistic transient stability assessment of power system considering wind power uncertainties and correlations", Int. J. Electr. Power Energy Syst., Vol. 117, p. 105649, 2020.

[10] Y. Li et al., "Coordinated scheduling for improving uncertain wind power adsorption in electric vehicles-Wind integrated power systems by multiobjective optimization approach", IEEE Trans. Ind. Appl., Vol. 56, No. 3, pp. 2238-2250, 2020.

[11] B. B. Adetokun, C. M. Muriithi, and J. O. Ojo, "Voltage stability assessment and enhancement of power grid with increasing wind energy penetration", Int. J. Electr. Power Energy Syst., Vol. 120, p. 105988, 2020.

[12] N. Gurung, R. Bhattarai, and S. Kamalasadan, "Optimal Oscillation Damping Controller Design for Large-Scale Wind Integrated Power Grid”, IEEE Trans. Ind. Appl., Vol. 56, No. 4, pp. 4225-4235, 2020.

[13] Y. Chi, Y. Xu, and R. Zhang, "Many-objective robust optimization for dynamic var planning to enhance voltage stability of a wind-energy power system", IEEE Trans. Power Deliv., 2020.

[14] B. Qin, H. Li, X. Zhang, T. Ding, K. Ma, and S. Mei, "Quantitative short-term voltage stability analysis of power systems integrated with DFIG-based wind farms", IET Gener. Transm. Distrib., Vol. 14, No. 19, pp. 4264-4272, 2020.

[15] S. Dadjo Tavakoli, E. Prieto-Araujo, E. Sánchez-Sánchez, and O. Gomis-Bellmunt, "Interaction assessment and stability analysis of the MMC-based VSC-HVDC link", Energies, Vol. 13, No. 8, p. 2075, 2020.

[16] G. Lee, D. Kwon, and S. Moon, "DC Current and Voltage Droop Control Method of Hybrid HVDC Systems for an Offshore Wind Farm Connection to Enhance AC Voltage Stability", IEEE Trans. Energy Convers., 2020.

[17] M. S. Javed, T. Ma, J. Jurasz, and M. Y. Amin, "Solar and wind power generation systems with pumped hydro storage: Review and future perspectives", Renew. Energy, Vol. 148, pp. 176-192, 2020.

[18] S. Gurung, F. Jurado, S. Naetiladdanon, and A. Sangswang, "Comparative analysis of probabilistic and deterministic approach to tune the power system stabilizers using the directional bat algorithm to improve system small-signal stability", Electr. Power Syst. Res., Vol. 181, p. 106176, 2020.

[19] J. Li, P. Liu, and Z. Li, "Optimal design and techno-economic analysis of a solar-windbiomass off-grid hybrid power system for remote rural electrification: A case study of west China", Energy, Vol. 208, p. 118387, 2020.

[20] A. U. Krismanto and M. Nadarajah, "Identification of Modal Interaction and Small Signal Stability in Autonomous Microgrid Operation", IET Gen. Transm. Distrib., 2017, doi: 10.1049/iet-gtd.2017.1219.

[21] A. U. Krismanto, N. Mithulananthan, and O. Krause, "Stability of Renewable Energy based Microgrid in Autonomous Operation", Sustain. Energy, Grids Networks, Vol. 13, pp. 134-147, 2018, doi: https://doi.org/10.1016/j.segan.2017.12.009.

[22] B. Zhang, M. Wang, and W. Su, "Reliability Analysis of Power Systems Integrated with High-Penetration of Power Converters", IEEE Trans. Power Syst., 2020.

[23] J.-H. Wu, H.-Y. Wang, W.-Q. Wang, and Q. Zhang, "A comprehensive evaluation approach for static voltage stability analysis in electric power grids", Electr. Power Components Syst., Vol. 47, No. 6-7, pp. 573-588, 2019.

[24] H. M. Sultan, A. A. Z. Diab, O. N. Kuznetsov, Z. M. Ali, and O. Abdalla, "Evaluation of the impact of high penetration levels of PV power plants on the capacity, frequency and voltage stability of Egypt's unified grid", Energies, Vol. 12, No. 3, p. 552, 2019.

[25] S. Barik and D. Das, "A novel Q- PQV bus pair method of biomass DGs placement in distribution networks to maintain the voltage of remotely located buses", Energy, Vol. 194, p. 116880, 2020.

[26] B. S. England and A. T. Alouani, "Real time voltage stability prediction of smart grid areas using smart meters data and improved Thevenin estimates", Int. J. Electr. Power Energy Syst., Vol. 122, p. 106189, 2020.

[27] A. I. Omar, S. H. E. A. Aleem, E. E. A. El-Zahab, M. Algablawy, and Z. M. Ali, "An improved approach for robust control of dynamic voltage restorer and power quality enhancement using grasshopper optimization algorithm", ISA Trans., 
Vol. 95, pp. 110-129, 2019.

[28] C. Mishra, R. Sen Biswas, A. Pal, and V. A. Centeno, "Critical clearing time sensitivity for inequality constrained systems", IEEE Trans. Power Syst., Vol. 35, No. 2, pp. 1572-1583, 2019.

[29] R. D. Muhammad, S. Herlambang, L. Dwi, and Y. Y. Muhammad, "Modal analysis and stability enhancement of $150 \mathrm{kV}$ Sulselrabar electrical system using PSS and RFB based on cuckoo search algorithm", Int. J. Electr. Eng. Informatics, Vol. 9, No. 4, pp. 800-812, 2017.

\section{Appendix}

Table 1: List of notations used in this paper

\begin{tabular}{|c|c|}
\hline Symbol & Meaning \\
\hline$V_{c i}$ & Cut in wind turbine speed \\
\hline$V_{c o}$ & Cut off wind turbine speed \\
\hline$V_{r}$ & Rated speed \\
\hline$P_{w}$ & $\begin{array}{l}\text { Power output at a particular } \\
\text { wind speed }\end{array}$ \\
\hline$P_{w r}$ & $\begin{array}{l}\text { Equivalent rated power output } \\
\text { of wind power plant }\end{array}$ \\
\hline$\varphi_{d P L L}$ & $\begin{array}{l}\text { Auxiliary state variable in D } \\
\text { axis }\end{array}$ \\
\hline$\varphi_{q P L L}$ & $\begin{array}{l}\text { Auxiliary state variable in } Q \\
\text { axis }\end{array}$ \\
\hline$\beta_{d g e n}$ & $\begin{array}{l}\text { Auxiliary state variable of outer } \\
\text { control loop of generator side } \\
\text { converter in D axis }\end{array}$ \\
\hline$\beta_{\text {qgen }}$ & $\begin{array}{l}\text { Auxiliary state variable of outer } \\
\text { control loop of generator side } \\
\text { converter in Q axis }\end{array}$ \\
\hline$i_{\text {dgen }}$ & $\begin{array}{l}\text { Generator actual current in D } \\
\text { axis }\end{array}$ \\
\hline$i_{\text {qgen }}$ & $\begin{array}{l}\text { Generator actual current in } \mathrm{Q} \\
\text { axis }\end{array}$ \\
\hline$m_{d g e n}^{*}$ & $\begin{array}{l}\text { Modulation index for } \\
\text { generator-side } \\
\text { axis }\end{array}$ \\
\hline$m_{\text {qgen }}^{*}$ & $\begin{array}{l}\text { Modulation } \begin{array}{l}\text { index } \\
\text { generator-side } \\
\text { axis }\end{array} \\
\text { conveter in } Q \\
\end{array}$ \\
\hline$\beta_{\text {dgrid }}$ & $\begin{array}{l}\text { Auxiliary state variable of outer } \\
\text { control loop of grid side } \\
\text { converter in D axis }\end{array}$ \\
\hline$\beta_{\text {qgrid }}$ & $\begin{array}{l}\text { Auxiliary state variable of outer } \\
\text { control loop of grid side } \\
\text { converter in Q axis }\end{array}$ \\
\hline$i_{\text {dgrid_ref }}$ & $\begin{array}{l}\text { Grid side current reference in D } \\
\text { axis }\end{array}$ \\
\hline$i_{\text {qgrid_ref }}$ & $\begin{array}{l}\text { Grid side current reference in } \mathrm{Q} \\
\text { axis }\end{array}$ \\
\hline$i_{\text {od }}$ & Actual current output in D axis \\
\hline$i_{o q}$ & Actual current output in D axis \\
\hline$m_{\text {dgrid }}^{*}$ & $\begin{array}{l}\text { Modulation index for grid-side } \\
\text { inverter in D axis }\end{array}$ \\
\hline
\end{tabular}

\begin{tabular}{|l|l|}
\hline$m_{\text {qgrid }}^{*}$ & $\begin{array}{l}\text { Modulation index for grid-side } \\
\text { inverter in Q axis }\end{array}$ \\
\hline
\end{tabular}

